University of Nebraska - Lincoln

DigitalCommons@University of Nebraska - Lincoln

Application of a strip-yield model to predict crack growth under variable-amplitude and spectrum loading - Part 2: Middle-cracktension specimens

\author{
B. Ziegler \\ Mississippi State University \\ Y. Yamada \\ Ohio Aerospace Institute at NASA Glenn Research Center \\ J.C. Newman Jr. \\ Mississippi State University, j.c.newman@ae.msstate.edu
}

Follow this and additional works at: https://digitalcommons.unl.edu/nasapub

Part of the Physical Sciences and Mathematics Commons

Ziegler, B.; Yamada, Y.; and Newman, J.C. Jr., "Application of a strip-yield model to predict crack growth under variable-amplitude and spectrum loading - Part 2: Middle-crack-tension specimens" (2011). NASA Publications. 100.

https://digitalcommons.unl.edu/nasapub/100

This Article is brought to you for free and open access by the National Aeronautics and Space Administration at DigitalCommons@University of Nebraska - Lincoln. It has been accepted for inclusion in NASA Publications by an authorized administrator of DigitalCommons@University of Nebraska - Lincoln. 


\title{
Application of a strip-yield model to predict crack growth under variable-amplitude and spectrum loading - Part 2: Middle-crack-tension specimens
}

\author{
B. Ziegler ${ }^{\text {a }}$, Y. Yamada ${ }^{\text {b }}$, J.C. Newman Jr. ${ }^{\text {a,* }}$ \\ ${ }^{\text {a } M i s s i s s i p p i ~ S t a t e ~ U n i v e r s i t y, ~ A e r o s p a c e ~ E n g i n e e r i n g, ~ M S ~ 39762, ~ U S A ~}$ \\ ${ }^{\mathrm{b}}$ Ohio Aerospace Institute at NASA Glenn Research Center, Cleveland, OH 44135, USA
}

\section{A R T I C L E I N F O}

\section{Keywords:}

Cracks

Fatigue-crack growth

Aluminum alloy

Crack closure

Stress-intensity factor

Plasticity

\begin{abstract}
A B S T R A C T
In previous work, fatigue-crack-growth tests were conducted on middle-crack tension, $M(T)$, and compact, $C(T)$, specimens made from the same $\mathrm{D} 16 \mathrm{Cz}$ (clad) aluminum alloy sheet. These tests were conducted over a wide range of stress ratios $\left(R=P_{\min } / P_{\max }=-0.5\right.$ to 0.75 ) to generate crack-growth-rate data from threshold to near fracture. These tests were used to generate the effective stress-intensity factor range ( $\left.\Delta K_{\text {eff }}\right)$ against rate curve using a crack-closure model. The analyses collapsed the rate data from both specimen types into a fairly narrow band over many orders of magnitude in rates using proper constraint factors. Constraint factors were established from single-spike overload and the constant-amplitude tests. Herein, the life-prediction code, FASTRAN, which is based on the strip-yield model concept, was used to calculate the crack-length-against-cycles under constant-amplitude (CA) loading and the single-spike overload (OL) tests; and to predict crack growth under variable-amplitude (VA) loading and simulated aircraft loading spectrum tests on the $M(T)$ specimens. The calculated crack-growth lives under CA and an OL tests were generally within $\pm 20 \%$ of the test results, but slower crack growth under the double-shear fatigue mode, rather than single shear, may be the reason for some of the larger differences. The predicted crack-growth lives for the VA and Mini-Falstaff spectrum tests were also short by $25-45 \%$. A modified model with some assumed notch constraint effects matched the spectrum tests quite well. Issues on the crack-starter-notch effects under spectrum loading are discussed, and recommendations are suggested on avoiding these notch effects.
\end{abstract}

(c) 2011 Elsevier Ltd. All rights reserved.

\section{Introduction}

In 2004, Schijve et al. [1] presented the results of various fatigue-crack-growth-rate tests on the aluminum alloy D16Cz (clad) sheet, which was considered to have crack-growth properties similar to the 2024-T3 alloy. Later, these test results were compared to calculations made with the NASGRO [2] life-prediction code by Skorupa et al. [3]. In the NASGRO calculations, the strip-yield model options were used. In the mid-1990's, the strip-yield model options in NASGRO were developed by the National Aerospace Laboratory [4] in a joint effort between the European Space Agency and the National Aeronautics and Space Administration. The model equations were similar to those developed in the FASTRAN life-prediction code [5], which are based on Elber's crack-closure concept [6] and the Dugdale strip-yield model [7]. The NASGRO code has two

\footnotetext{
* Corresponding author. Tel.: +1 662325 1521; fax: +1 6623257720 .

E-mail address: j.c.newman@ae.msstate.edu (J.C. Newman Jr.).
} 


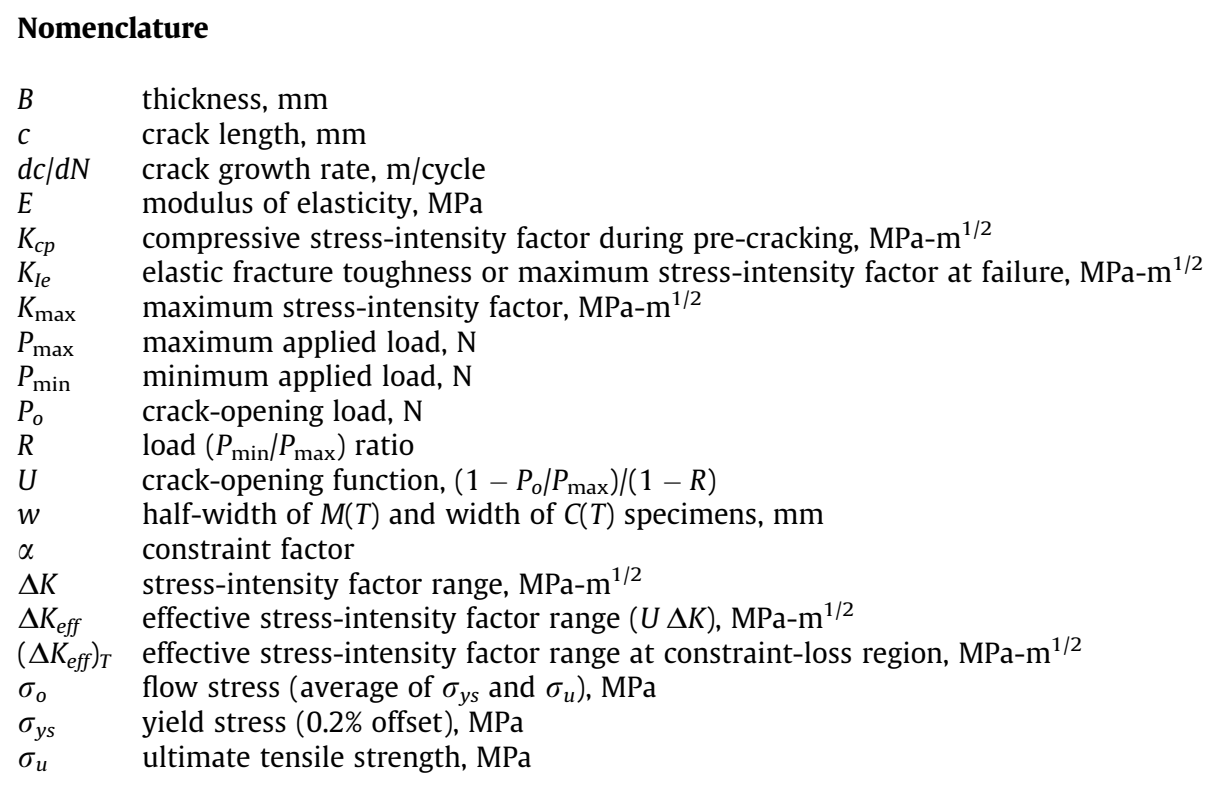

strip-yield model options: (1) variable constraint in the plastic-zone region, and (2) constant constraint in the plastic-zone region. Both options were used and the article stated that "no analysis option enabled to reproduce crack growth retardation observed after application of a single overload cycle ... Improving the predictions for VA (variable-amplitude) loading would require choosing lower values of the fitting parameter $(\alpha)$ which, however, would worsen the predictions for CA (constantamplitude) loading" [3]. The unexpected inconsistencies found in these comparisons and the emphasis on the constraint-loss regime has inspired the present work.

Using material provided by the research group in Poland (M. Skorupa and T. Machniewicz, University of Science and Technology), a series of fatigue-crack-growth tests were performed on compact, $C(T)$, specimens [8] machined from previously fractured middle-crack tension, $M(T)$, specimens. Testing included constant-amplitude loading at several stress ratios $(R)$, a single spike overload test, and spectrum tests using Mini-Falstaff + , a spectrum derived from Mini-Falstaff $[9,10]$ consisting of only tensile loads. Test data generated under constant-amplitude loading on the $C(T)$ specimens was combined with the test data by Schijve et al. [1] on $M(T)$ specimens to develop a multi-linear curve describing the relationship between crackgrowth rate $(d c / d N)$ and the effective stress-intensity factor $\left(\Delta K_{\text {eff }}\right)$ using proper constraint factors. The constraint factor models the elevation of the flow stress around a crack front due to the tri-axial stress state [11,12]. The constrant factor $(\alpha)$ is a key parameter in the correlation of fatigue-crack-growth-rate data and the prediction of crack growth under variable-amplitude loading. It was determined many years ago that constant-amplitude test data was necessary, but not sufficient to establish the constraint factors [13,14]. Single-spike or repeated-spike overload tests are more sensitive to constraint factors than CA loading. It would be prudent to conduct tests under spike overloads or other VA loading to validate the selection of the constraint factors. Of course, the constant-amplitude tests at various stress ratios $(R)$ may be used to estimate an initial value of the constraint factor. In addition, a constraint-loss regime [15] occurs as the plastic-zone size approaches the sheet thickness (plane strain to plane stress), that allows slip-bands to develop through the thickness, and the crack surfaces develop full slant (single shear) or double-shear fracture [16,17].

This research work is organized in two papers. The objectives of the first paper [8] were to present test data on compact, $C(T)$, specimens, to develop the effective stress-intensity factor against rate relation and to determine the constraint factors for the D16Cz alloy. Herein, the second paper presents test data on the $M(T)$ specimens [1] and predicts crack growth under a single-spike overload, variable-amplitude (block) loading, and the Mini-Falstaff spectrum loading. The following will present and discuss the specifics of the material, specimens tested, test data analyses, types of fatigue loading applied, the crackgrowth analyses performed and a comparison of test and analyses.

\section{Material}

The material used was the Russian alloy D16CzATWH, which appears to be similar the American alloy 2124. It is a high purity clad alloy. Tensile testing performed by Schijve et al. [1] determined the mechanical properties to be $\sigma_{y s}=335 \mathrm{MPa}$, $\sigma_{u}=457 \mathrm{MPa}$ and an elongation of 22\%. The high elongation (as compared to 2024-T3) is likely explained by the low impurity content (Fe and $\mathrm{Si}$ ) and the crack-growth properties are considered to be similar to the 2024-T3 alloy [1]. 


\section{Specimens}

The research group in Poland (M. Skorupa and T. Machniewicz, University of Science and Technology) had conducted crack-growth tests on $M(T)$ specimens made of the D16Cz alloy under constant-amplitude (CA) loading, a single-spike overload (OL), variable-amplitude (VA) block loading, and simulated spectrum loading using Mini-Falstaff $[9,10]$. The sheet thickness was $B=4 \mathrm{~mm}$. All of these tests were conducted under laboratory air and at room temperature. They had also provided the current authors with nine broken halves of some specimens.

Fatigue-crack-growth tests had previously been carried out on $M(T)$ specimens [1], as shown in Fig. 1a. A central crackstarter notch to initiate a fatigue crack was provided by a narrow saw cut from a small hole. Specimens were cleaned and polished to $1-\mu \mathrm{m}$ to facilitate visual crack measurement (on only one side of the specimen). As a result, the thickness of the cladding layer at this side was reduced to about $0.04 \mathrm{~mm}$. Specimens were $100 \mathrm{~mm}$ wide and about $500 \mathrm{~mm}$ long with a nominal thickness of $4 \mathrm{~mm}$. The saw cut notch was $8-\mathrm{mm}$ by $0.5-\mathrm{mm}$ with a center circular hole of 2-mm radius, see Fig. $1 \mathrm{~b}$.

Standard ASTM plan-form $C(T)$ specimens were machined from the broken halves of a number of previously tested $M(T)$ specimens in the as-received thickness. Most $C(T)$ specimens came from only one half of an $M(T)$ specimen, however, there were two $C(T)$ specimens machined from one specimen. Crack-growth and fracture tests were conducted on the $76.2 \mathrm{~mm}$ wide $C(T)$ specimens over a range of stress ratios $\left(R=P_{\min } / P_{\max }=0.1-0.75\right)$, a single-spike overload, and under simulated aircraft spectrum loading using Mini-Falstaff+, a spectrum derived from Mini-Falstaff $[9,10]$ consisting of only tensile loads. The details on specimen preparation, testing and crack-growth analyses are given in Ref. [8].

\section{FASTRAN - plasticity-induced crack-closure model}

The plasticity-induced crack-closure model was developed for a central through crack and two-symmetric through cracks emanating from a circular hole in a finite-width plate subjected to uniform remote applied stress. The model was based on Elber's crack-closure concept [6] and the Dugdale strip-yield model [7], but modified to leave plastically deformed material in the wake of the crack. The details of the model are given elsewhere and will not be presented here (see Newman [11,12]). One of the most important features of the model is the ability to model three-dimensional constraint effects. A constraint factor $\alpha$ is used to elevate the flow stress $\left(\sigma_{o}\right)$ at the crack tip to account for the influence of stress state $\left(\alpha \sigma_{o}\right)$ on plastic-zone sizes and crack-surface displacements. (The flow stress $\sigma_{o}$ is taken as the average between the yield stress $\sigma_{y s}$ and ultimate tensile strength $\sigma_{u}$ of the material.) For plane-stress conditions, $\alpha$ is equal to unity (original Dugdale model); and for simulated plane strain conditions, $\alpha$ is equal to 3 . The calculations performed herein were made with FASTRAN Version 3.82. The crack-growth relation used in FASTRAN is a multi-linear relation with terms to account for threshold and fracture, and is

$$
d c / d N=C_{1 i}\left(\Delta K_{\text {eff }}\right) C_{2 i}\left[1-\left(\Delta K_{o} / \Delta K_{\text {eff }}\right)^{p}\right] /\left[1-\left(K_{\max } / K_{\text {Ie }}\right)^{q}\right]
$$

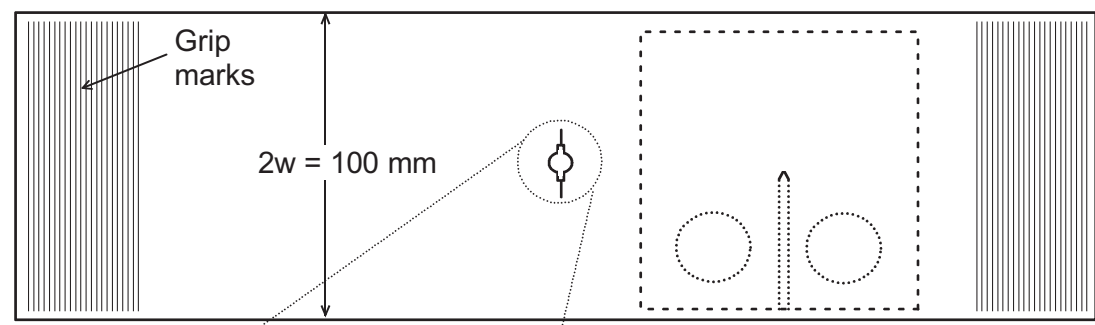

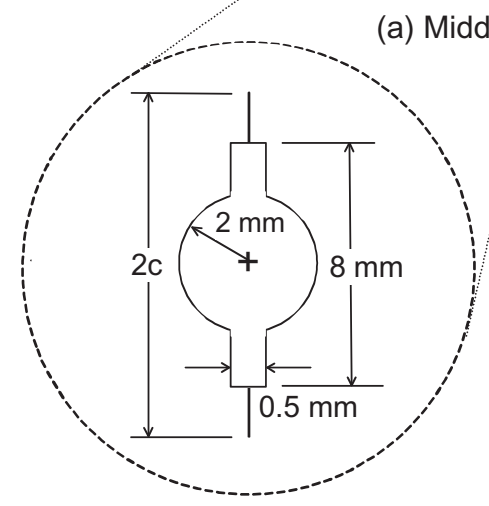

(b) Notch details

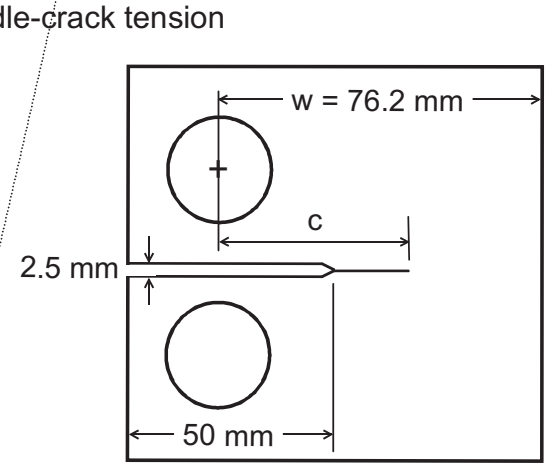

(c) Compact

Fig. 1. Layout and dimensions of $M(T)$ and $C(T)$ specimens. 
where $C_{1 i}$ and $C_{2 i}$ are the coefficient and power for each linear segment, $\Delta K_{\text {eff }}$ is the effective stress-intensity factor, $\Delta K_{o}$ is the effective threshold, $K_{\max }$ is the maximum stress-intensity factor, $K_{I e}$ is the elastic fracture toughness (which is, generally, a function of crack length, specimen width, and specimen type), $p$ and $q$ are constants selected to fit test data in either the threshold or fracture regimes. Whenever the applied $K_{\max }$ value reached or exceeded $K_{I e}$, then the rate would go to infinity and the specimen or component would fail. The Two-Parameter Fracture Criterion (TPFC) [13] was used to correlate [8] and to predict the failure loads ( or $K_{I e}$ ) on both $C(T)$ and $M(T)$ specimens. Herein, $\Delta K_{o}$ was set to zero and the threshold behavior was modeled with multi-linear segments and the threshold behavior was assumed to be independent of $R$. The multi-linear (table-lookup) form is used because many materials, especially aluminum alloys, show sharp changes in the crack-growthrate curves at unique values of rates. Further details on the fatigue-crack-growth analyses are given in Ref. [8], and will not be presented here.

\section{Constant-amplitude loading}

To make crack-growth predictions, $\Delta K_{\text {eff }}$ as a function of the crack-growth rate must be obtained over the widest possible range in rates (from threshold to fracture), especially if spectrum loading predictions are required. Under constantamplitude (CA) loading, the only unknown in the analysis is the constraint factor, $\alpha$. The constraint factor(s) were determined by finding (by trial-and-error) a value (or values) that would correlate the CA crack-growth-rate data over a wide range in stress ratios. But CA data alone is not sufficient to establish the proper constraint factors. Single-spike overload and/or repeated spike overload tests have been used to help determine the proper constraint factors [14,15]. Using the test data on $C(T)$ [8] and $M(T)$ [1] specimens, the $\Delta K_{\text {eff }}$-rate relation for the D16Cz aluminum alloy was developed in Ref. [8].

The $\Delta K$-rate data from both $M(T)$ and $C(T)$ specimens are shown in Fig. 2 over a wide range of rates and stress ratios. (Note

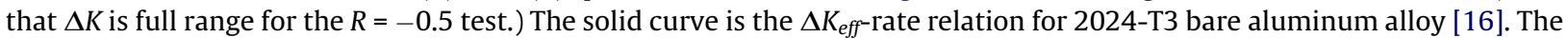
$C(T)$ and $M(T)$ data at $R=0.75$ agreed well with each other and also agreed with the 2024-T3 curve. Most aluminum alloys show a rapid rise in rates around $1 e-8 \mathrm{~m} /$ cycle (transition from lower plateau to higher rates), but the D16Cz alloy exhibited a very rapid rise at low $R$ and a more gradual rise at $R=0.75$.

The data shown in Fig. 2 was analyzed with the crack-closure model and these results are shown in Fig. 3 for the $M(T)$

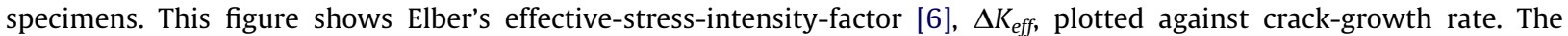
crack-opening stresses from the crack-closure model, FASTRAN, were used to correlate these data [12]. Again, the solid curve is the $\Delta K_{\text {eff }}$-rate relation for 2024-T3 bare aluminum alloy [16]. The constraint-loss regime has been associated with the transition from flat-to-slant crack growth. The diamond symbols show rate measurements made on the $M(T)$ specimens tested under the CA loading conditions where the tensile-to-shear-mode transition occurred [1]. However, a constraint loss may occur without the flat-to-slant crack-growth behavior [17,18], when the plastic-zone size is the order of the sheet thickness [19]. The vertical dashed line shows the calculated $\left(\Delta K_{e f f}\right)_{T}$ value, where the flat-to-slant crack-growth transition should occur for this sheet material [16]. Currently, the selection of the constraint factors and their associated rates, during the constraint-loss regime, has to be obtained by trial-and-error. It is, however, suspected that the start of the slant-crack growth regime is independent of sheet thickness and occurs as the plastic zone at the free surface begins to allow shear deformations. But the attainment of the fully slant-crack growth $\left(45^{\circ}\right)$ is a function of the sheet thickness. For crack-growth rates less

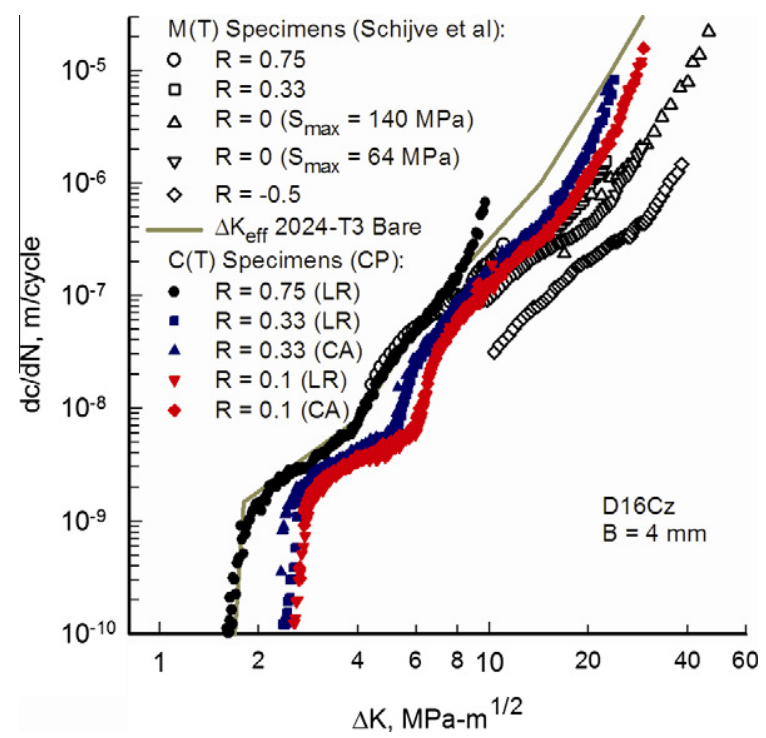

Fig. 2. LEFM $\Delta K$ against rate for $M(T)$ and $C(T)$ specimens. 


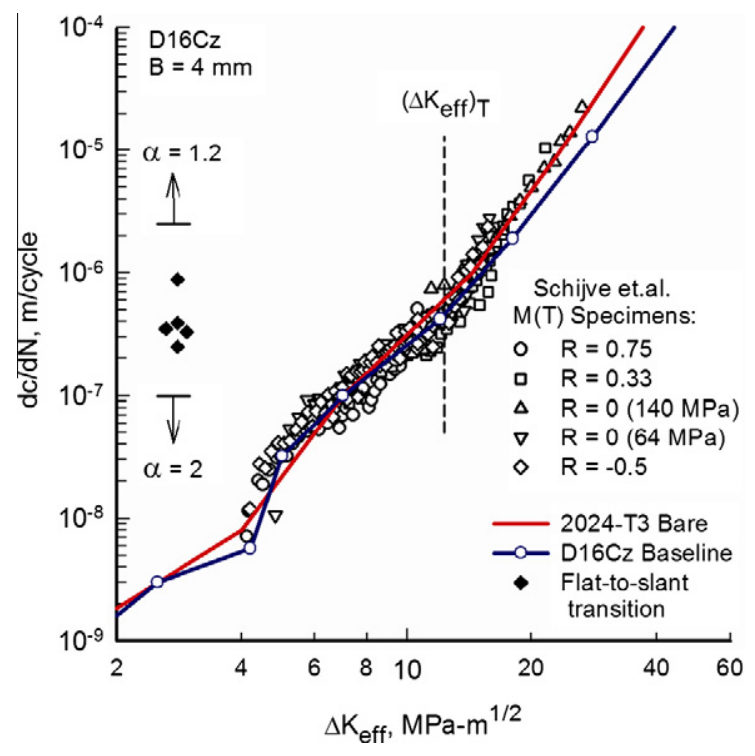

Fig. 3. Effective stress-intensity factor $\left(\Delta K_{\text {eff }}\right)$ against rate for $M(T)$ specimens.

than $1 e-7 \mathrm{~m} /$ cycle, a constraint factor, $\alpha_{1}$, of 2 was used, but above a rate of $2.5 e-6 \mathrm{~m} /$ cycle, a constraint factor, $\alpha_{2}$, of 1.2 was used. The compressive constraint factor, $\beta$, was assumed to be unity because a closed crack has no singular behavior. The crack-closure model correlated the fatigue-crack-growth rate data in a fairly tight band over several orders-of-magnitude in rates.

In Fig. 3, the large open circles with the solid lines show the $\Delta K_{\text {eff }}$-rate baseline relation chosen to fit these data and the $C(T)$ data from Ref. [8]. For very high rates, the selected curve is lower than the test data because the fracture term in Eq. (1) accounts for the more rapid rise to fracture, as will be shown later. Fatigue-crack-growth rates were calculated from the baseline relation, as a multi-linear (table-lookup) input (Eq. (1)) in the FASTRAN code. The particular values are given in Ref. [8] (Table 1).

Because the tests conducted by Schijve et al. [1], and used by Skorupa et al. [3], to assess the NASGRO life-prediction code, occurred primarily in the constraint-loss regime, a comparison of some of the $M(T)$ test results and the calculated results from the equation used to model the crack-growth behavior is shown in Fig. 4. This figure shows applied $\Delta K$ against rate for the high- $R$ test and the two tests conducted at $R=0$. The symbols show the test data and the solid curve with open circles show the $\Delta K_{\text {eff }}$-rate baseline curve. FASTRAN calculations were made for the three test cases with an initial crack length of

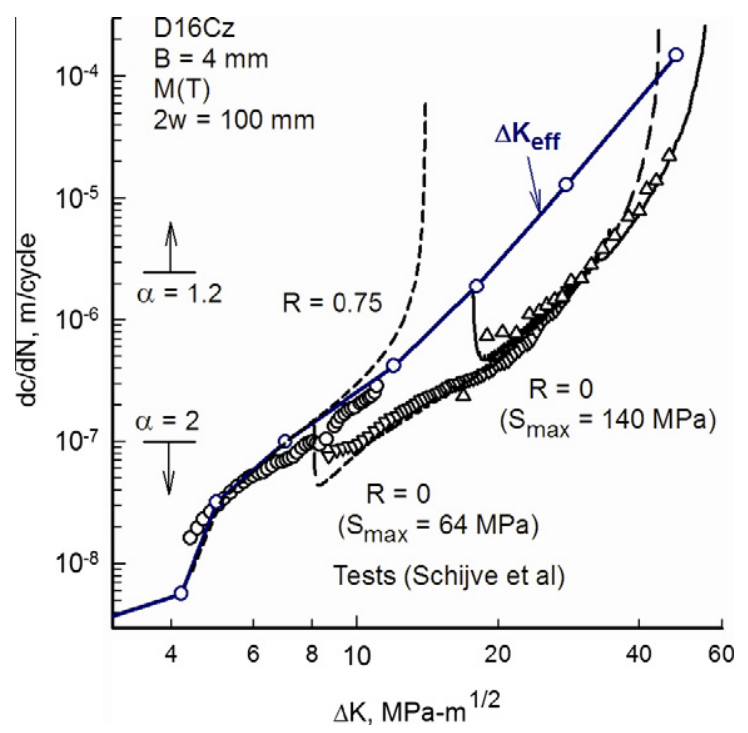

Fig. 4. Crack-growth rates for $M(T)$ specimens tested at $R=0.1$ and model calculations. 


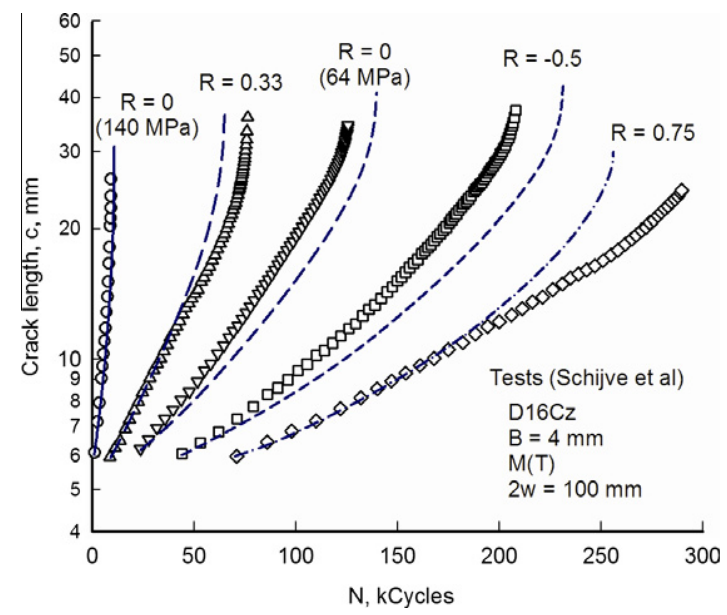

Fig. 5. Crack length against cycles for $M(T)$ specimens and model calculations under CA loading.

$5 \mathrm{~mm}$. Because the crack in the high- $R$ test is essentially fully open, the $\Delta K$ values are $\Delta K_{\text {eff }}$ and the calculated curve agrees with the baseline curve until the fracture term in Eq. (1) becomes significant. For the $R=0$ test simulations, the initial crack is fully open and the initial $\Delta K$ values are equal to $\Delta K_{\text {eff, }}$ but the calculated curve rapidly drops as crack closure develops. Once the crack-closure behavior has nearly stabilized, the steady-state curve is calculated and the curve approaches fracture as the $K_{\max }$ value reaches $K_{I e}$. In all cases, the calculated curves in Fig. 4 agreed well with the test data, but some discrepancies were observed in the early stages for each test.

A comparison of calculated crack-length-against-cycles for the $M(T)$ specimens subjected to CA loading are shown in Fig. 5. The test data are shown as symbols and the FASTRAN calculations are shown as curves. For clarity, the test data and curves have been offset in cycles to separate the curves. The results are shown on a log crack length axis to more clearly show the results in the early stages of crack growth. Because of transients in the early stages, all test data and curves are started at a crack length of about $6 \mathrm{~mm}$. It is suspected that the results at high- $R(0.33$ and 0.75$)$ are influenced by the development of the double-shear mode instead of single-shear (slant) crack growth. See the results at $R=0.33$ and 0.75 at a crack length of about $12-\mathrm{mm}$, where there is a noticeable change in the shape of the test data curve. It has also been observed that cracks growing under the double-shear mode tend to grow slower and have higher fracture toughness than a crack growing under single slant shear crack growth. But the agreement between the tests and model calculations was within $\pm 20 \%$.

\section{Single-spike overload}

Tests on single-spike overloads (OL) on both the $M(T)$ [1] and $C(T)$ [8] specimens helped to substantiate the selection of the constraint factors $(\alpha, \beta)$ in the crack-closure model. Fig. 6 shows a comparison between the OL test result and model cal-

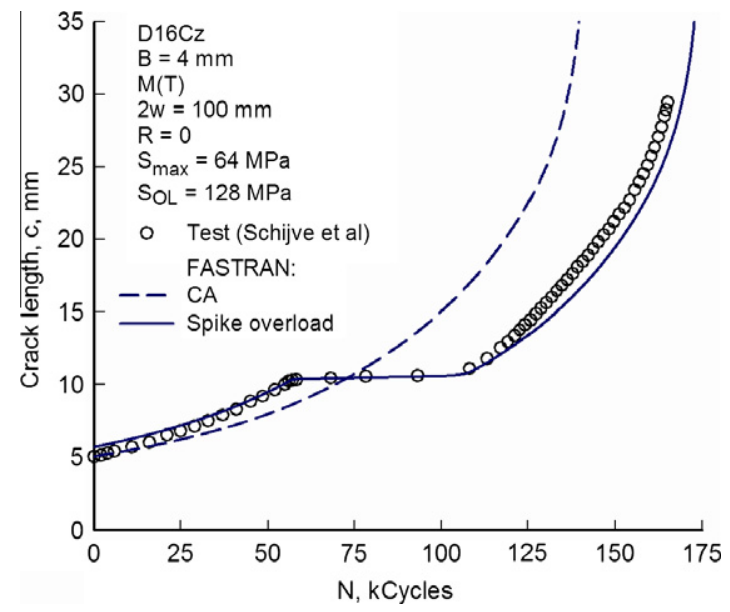

Fig. 6. Crack length against cycles for a $M(T)$ specimen and model calculations for a single-spike overload. 
culations for the $M(T)$ specimen. The model over predicted the CA portion from the initial crack length to the OL event, so the calculated curve was anchored at the number of cycles where the OL was applied. The agreement between the model and test data was within $10 \%$ and demonstrated that delayed retardation could be modeled very well, if the proper constraint factors are used.

\section{Variable-amplitude loading}

Schijve et al. [1] conducted tests under several variable-amplitude (VA) loading sequences, as shown in Fig. 7. The baseline loading was at $R=0.33$ with periodic under loads (UL) and periodic overloads (OL). Types II and III are very similar sequences except that the OL is either preceded by an UL or followed by an UL. Fig. 8 shows the test data and model predictions for the three types of VA loading. The crack-growth lives for Types II and III are longer than Type I due to the overloads, but the fact that Type III had a longer life than Type II was a surprise to Schijve et al. [1], Skorupa et al. [3] and the current authors. The model, however, predicted the correct trend. But the predicted results were all about 30\% short of the test data. Whether cracks in these specimens grew into the double-shear mode could not be determined, but could possibly explain why these tests all produced longer crack-growth lives than the model. (In Ref. [8], two $C(T)$ specimens tested at $R=0.33$ both developed the double-shear mode before fracture; while three $C(T)$ tests at $R=0.1$ loading developed the single-shear mode.)

\section{Spectrum loading}

In Schijve et al. [1], three Mini-Falstaff tests were carried out with $S_{\text {peak }}$ values of 247.5, 230 and 220 MPa, respectively. The Mini-Falstaff sequence has 9006 cycles, which is equivalent to 200 flights [9,10]. In view of the random sequence of small and large load amplitudes, the tests were conducted with an approximately constant loading rate. As a result, one per-

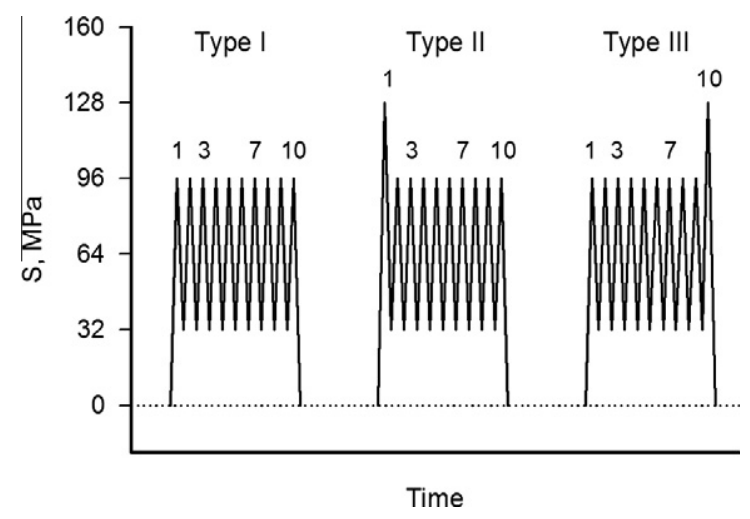

Fig. 7. Variable-amplitude (block) loading applied to $M(T)$ specimens.

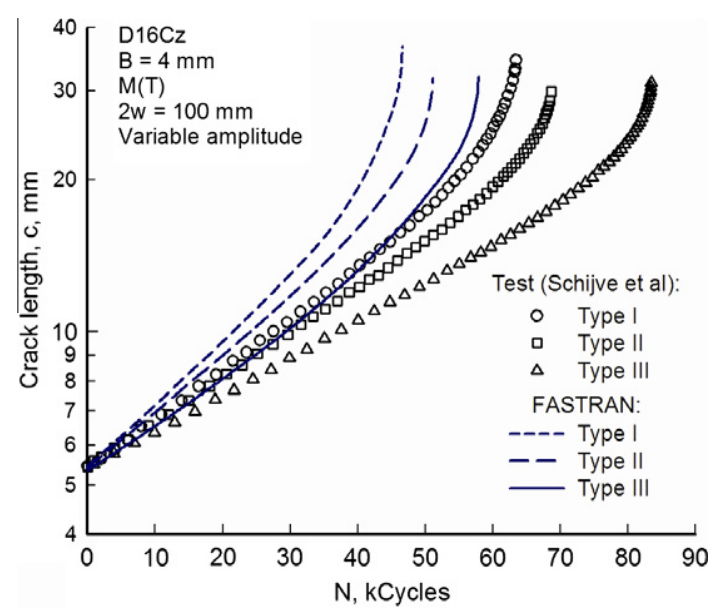

Fig. 8. Crack length against cycles for $M(T)$ specimens and model calculations for variable-amplitude (block) loading. 
iod 9006 cycles occurred in about $38 \mathrm{~min}$ (corresponds to an average frequency of $4 \mathrm{~Hz}$ ) [1]. Some of the Mini-Falstaff sequence is shown in Fig. 9.

Tests were conducted with three different maximum applied stress levels and these results are shown in Fig. 10, as symbols. It appears that fatigue pre-cracking was not performed on these specimens. Two tests had an initial crack length $\left(c_{i}\right)$ of $3.4 \mathrm{~mm}$, while one specimen had a $5.5 \mathrm{~mm}$ crack length. The test data is shown for crack lengths of $5.5 \mathrm{~mm}$ to failure. The model predictions are shown by the solid and dashed curves, which predicted faster crack growth from the notch than the tests and the crack-growth lives fell significantly short of the test data by about $45 \%$. The reason for the large discrepancy is not known, but could be related to the constraint factors and state-of-stress for crack initiating at a saw-cut notch. Wanhill and Schra [20] have noted "Changing the starter notch geometry resulted in significant differences in initial non-stabilized fatigue crack growth behavior (under flight simulation loading) ...". In addition, Newman et al. [21] had also noted that cracks growing from an EDM notch at a hole under spectrum loading were predicted to grow much faster than the test results on a 7075 alloy. The results herein seem to be similar.

FASTRAN can model the influence of a crack emanating from a notch, not on how the stress-intensity factors are affected by the notch, but on the lack of closure along the notch surfaces, as shown in Fig. 11a. Under general cyclic loading, the notch surfaces will not close and, thus, the crack surfaces must totally resist the contact (or closure) stresses. This will cause the crack-front material and crack surfaces to yield more in compression than if the notch surfaces were allowed to contact. The reverse yielding will cause lower crack-opening stresses and, subsequently, faster crack growth.

In FASTRAN, the constraint variations (tensile and compressive constraint) are controlled by the "crack". When a crack is fully open, the constraint factor $(\alpha)$ is high, like plane strain, but when the crack surfaces close, the crack-front singularity is lost and the stress state is assumed to be uniaxial. Thus, the compressive constraint factor, $\beta$, is assumed to be unity for the material in front and behind the crack tip. However, under tensile loading, a notch would have a high constraint factor, like a crack $(\alpha=2)$, and the notch-root material may yield under the applied loading. Upon unloading, the material at the notch

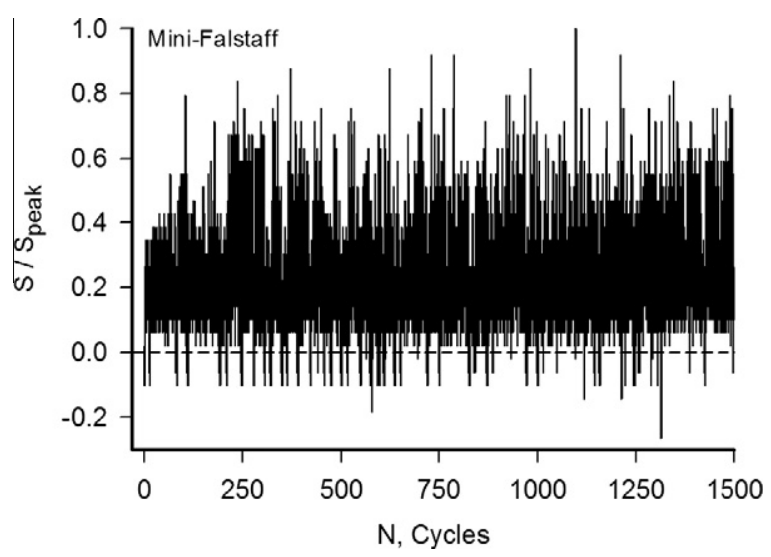

Fig. 9. Mini-Falstaff spectrum loading sequence.

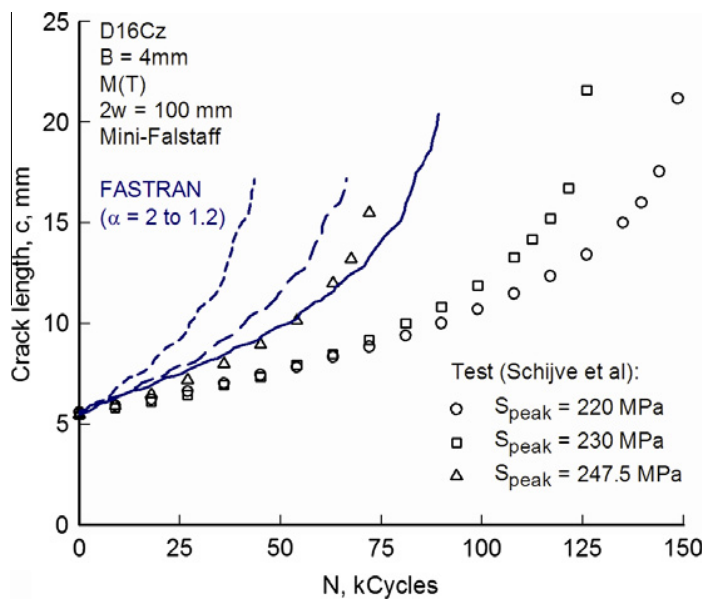

Fig. 10. Crack length against cycles for $M(T)$ specimens and model calculations for Mini-Falstaff spectrum loading. 


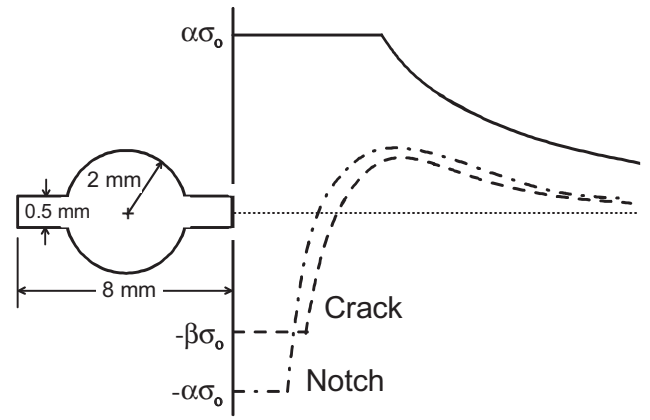

(a) Constraint

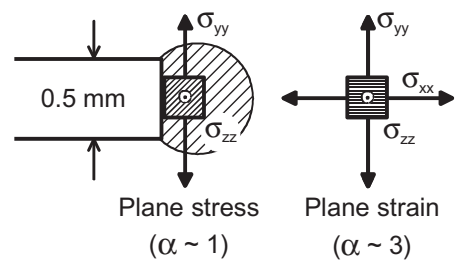

(b) Stress state

Fig. 11. Three-dimensional stress states and yielding around crack-starter notches and cracks.

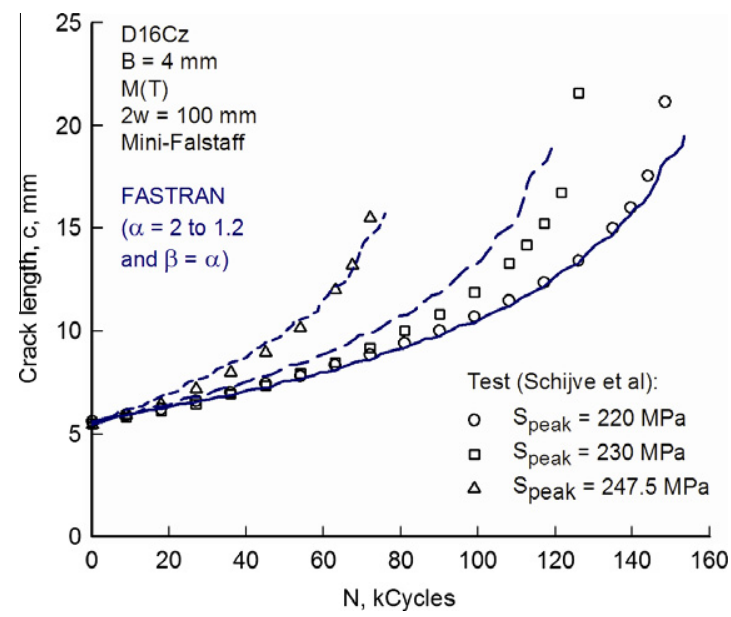

Fig. 12. Crack length against cycles for $M(T)$ specimens and modified model calculations for Mini-Falstaff spectrum loading.

root would then yield in compression, but with a higher compressive constraint factor than a closed crack (notch surfaces do not close). Thus, the plastic material at the notch root would "not" yield in compression as much as that for a crack because the compressive constraint factor $(\beta)$ would be high, like $\alpha$, see Fig. 11a. Thus, preventing the notch-root material from yielding would produce high closure stresses and slower crack-growth rates.

In addition, the state-of-stress at the edge of a notch is under plane-stress conditions (bi-axial stress state, $\sigma_{x x}=0$ ), as shown in Fig. 11b. Thus, more plastic yielding (larger plastic deformation) will occur at the notch than if a crack is present. As the crack grows, the constraint will build up and approach plane-strain conditions (tri-axial stress state). The plane-stress yield zone will cause more residual plastic deformations along the crack surfaces, higher crack-opening loads and slower crack-growth rate.

Some analyses were made with FASTRAN making the compressive constraint factor, $\beta$, equal to the tensile constraint factor, $\alpha$. Thus, $\beta=\alpha$ throughout the complete crack-growth process. Initially, this is an appropriate state, but as the crack grows, the compressive constraint factor should transition back to unity (if the $\beta=1$ is an appropriate condition for a crack). These analysis results are shown in Fig. 12, which agreed very well with the spectrum crack-growth measurements.

Further study is required to resolve these issues on constraint and state-of-stress for spectrum crack growth from notches. It is recommend that cracks be initiated and grown under low CA loading (may need to use some compression cycles to help initiate cracks at low stress-intensity factors) that will not yield the notch root significantly in tension allowing the crack to reach a steady-state condition with a known CA crack-opening behavior. Then the spectrum loading could be applied.

\section{Discussion of results}

The test program conducted by Schijve et al. [1] on the D16Cz clad aluminum alloy, and used by Skorupa et al. [3], to assess the NASGRO strip-yield model options, produced results that were primarily in the "constraint-loss regime". This is a difficult region because of the uncertainties in the constraint factors and the proximity of fracture conditions. The test 
program conducted on $C(T)$ specimens [8] made of the same exact material generated fatigue-crack-growth-rate data from threshold to near fracture for stress ratios of $0.1,0.33$ and 0.75 . The CA test data from the $M(T)$ and $C(T)$ specimens for the same stress ratio agreed very well. Some differences were observed in the fracture region because the stress-intensity factor does not correlate fracture conditions very well. Thus, a Two-Parameter Fracture Criterion (TPFC) was used to help model fatigue-crack growth as the cracks grew to failure. The TPFC tended to work well on both specimen types (tension and bending) using the same fracture constants $\left(K_{F}\right.$ and $m$ ).

As the cracks grew to failure under cyclic loading, it was observed that the higher $R$ ratio tests tended to show more double-shear fatigue surfaces than the low $R$ tests, which tended to develop single shear (slant) fatigue surfaces. This change in failure mode has also been associated with the constraint-loss regime. In other studies, it had also been observed that double-shear failure modes promote slower crack growth and higher fracture toughness. This may explain some of the under predictions made with the strip-yield model for high $R$ loading.

A rapid rise in rate behavior was observed between the lower and upper plateaus around $1 e-8 \mathrm{~m} / \mathrm{cycle}$. A few data points in the early stages of fatigue-crack growth in the $M(T)$ specimens tended to match the rapid-rise region observed in the $C(T)$ specimens. The slope of the data in this region appeared to be the same for the two low $R$-values (four tests), but the $R=0.75$ results (one test) exhibited a slightly lower slope. A difference was also observed in the threshold region for the $\Delta K_{e f f}$-rate data with the two low $R$ ratio results agreeing and producing a slightly higher threshold (17\%) than the $R=0.75$ test results. However, the high- $R$ results were selected in the table-lookup method to model the threshold behavior. Overall, the CA data correlated very well between both specimen types over a wide range in rates and stress ratios.

The single-spike overload test and the spectrum tests on the $C(T)$ specimens demonstrated that retardation and acceleration behavior could be accurately modeled with the strip-yield model once proper constraint factors were selected and the constraint-loss regime established.

\section{Concluding remarks}

In previous work, fatigue-crack-growth tests were conducted on middle-crack tension, $M(T)$, and compact, $C(T)$, specimens made from the same $\mathrm{D} 16 \mathrm{Cz}$ (clad) aluminum alloy material. These tests were conducted over a wide range of stress ratios $\left(R=P_{\min } / P_{\max }=-0.5\right.$ to 0.75$)$ to generate crack-growth-rate data from threshold to near fracture. These tests were used to generate the effective stress-intensity factor range $\left(\Delta K_{\text {eff }}\right)$ against rate curve using a crack-closure model. The analyses collapsed the rate data from both specimen types into a fairly narrow band over many orders of magnitude in rates using constraint factors. Constraint factors were established from single-spike overload and the constant-amplitude tests. Herein, the life-prediction code, FASTRAN, which is based on the strip-yield model concept, was used to calculate the crack-length-against-cycles under constant-amplitude (CA) loading and the single-spike overload (OL) tests; and to predict crack growth under variable-amplitude (VA) loading and simulated aircraft loading spectrum tests on the $M(T)$ specimens. The calculated crack-growth lives under CA and the OL tests were generally within $\pm 20 \%$ of the test results, but slower crack growth under the double-shear fatigue mode, rather than single shear, may be the reason for some of the larger differences. The predicted crack-growth lives for the VA and Mini-Falstaff spectrum tests were also short by 25-45\%. A modified model with some assumed notch constraint effects matched the spectrum tests quite well. Issues on the crack-starter notch effects under spectrum loading are discussed, and recommendations are suggested on avoiding these notch effects.

\section{Acknowlegments}

The authors thank Professors M. Skorupa and T. Machniewicz, University of Science and Technology, Kraków, Poland, and Professor J. Schijve, Delft University of Technology, Delft, Netherlands, for providing the D16Cz alloy material and the test data on the $M(T)$ specimens. The US Army under a sub-contract through Georgia Tech (Dr. A. Makeev) to Mississippi State University (MSU) sponsored this study.

\section{References}

[1] Schijve J, Skorupa M, Skorupa A, Machniewicz T, Gruszczynski P. Fatigue crack growth in the aluminum alloy D16 under constant and variable amplitude loading. Int J Fatigue 2004;26:1-15.

[2] NASGRO reference manual (version 4.02). Southwest Research Institute and NASA Johnson Space Center; 2002.

[3] Skorupa M, Machniewicz T, Schijve J, Skorupa A. Application of the strip-yield model from the NASGRO software to predict fatigue crack growth in aluminum alloys under constant and variable amplitude loading. Engng Fract Mech 2007;74:291-313.

[4] de Koning AU, ten Hoeve HJ, Henriksen TK. Description of crack growth using the strip-yield model for computation of crack opening loads, crack tip stretch, and strain rates, ASTM STP 1343, West Conshohocken, PA; 1999. p. 459-74.

[5] Newman Jr JC. FASTRAN-II - a fatigue crack growth structural analysis program. NASA TM 104159; 1992.

[6] Elber W. The significance of fatigue crack closure, vol. 486. ASTM STP; 1971. p. 230-42.

[7] Dugdale DS. Yielding of steel sheets containing slits. J Mech Phys Solids 1960;8:100-4.

[8] Yamada Y, Ziegler B, Newman Jr JC. Application of a strip-yield model to predict crack growth under variable-amplitude and spectrum loading - Part 1 : Compact specimens. Engng Fract Mech, this issue.

[9] FALSTAFF-a description of flight aircraft standard for fatigue evaluation, combined report of F\&W (Switzerland), LBF (Darmstadt), NLR (Amsterdam) and IABG (Munich); 1976.

[10] Murakami Y, editor. The rainflow method in fatigue, international symposium on fatigue damage measurement and evaluation under complex loadings, Fukuoka, Japan; 1991. 
[11] Newman Jr JC. A crack-closure model for predicting fatigue crack growth under aircraft spectrum loading, vol. 748. ASTM STP; 1981. p. 53-84.

[12] Newman Jr JC. A crack opening stress equation for fatigue crack growth. Int J Fract 1984;24. p. R131-5.

[13] Newman Jr JC. Fracture analysis of various cracked configurations in sheet and plate materials, ASTM STP 605, Philadelphia, PA; 1976. p. 104-23.

[14] Newman Jr JC, Dawicke DS. Prediction of fatigue crack growth in a high-strength aluminum alloy under variable-amplitude loading. Adv Fract Res 1989;ICF-7:945-52.

[15] Newman Jr JC. Prediction of crack growth under variable-amplitude loading in various materials. In: International conference on engineering against fatigue, Sheffield, United Kingdom; 1997. p. 261-8.

[16] Newman Jr JC. Effects of constraint on crack growth under aircraft spectrum loading. In: Beukers A et al., editors. Fatigue of aircraft materials. Delft University Press; 1992. p. 83-109.

[17] Schijve J. Significance of fatigue cracks in micro-range and macro-range, ASTM STP 415, Philadelphia, PA; 1967. p. 415-59.

[18] Schijve J. Shear lips on fatigue fractures in aluminum sheet material. Engng Fract Mech 1981;14:789-800.

[19] Newman Jr JC, Bigelow CA, Shivakumar KN. Three-dimensional elastic-plastic finite-element analyses of constraint variations in cracked bodies. Engng Fract Mech 1993;46(1):1-13.

[20] Wanhill RJH, Schra L. The influence of starter notches on flight simulation fatigue crack growth. NLR Technical Publication TP95127L; 1995.

[21] Newman Jr JC, Brot A, Matias C. Improved crack growth calculations in 7075-T7351 aluminum alloy under various aircraft load spectra. Engng Fract Mech 2004;71:2347-63. 